taken to prevent premature adherence to the nail, which may cause pocketing of pus and result in further spread under the nail. Occasionally a lateral pulp infection produces a subcuticular component beside the nail. Careful inspection of the abscess in paronychia will reveal the track to the deep component when it is present.

Pulp Infection.-(a) Subcuticular purulent blister: The blister is completely unroofed by snipping away the raised cuticle. The floor is mopped dry and inspected for a track into the pulp. If found, its extent and direction are measured by probing, and the opening is then enlarged in the appropriate direction. Probing should include a deliberate search for bare bone. (b) No subcuticular blister but pus diagnosed by localized tenderness: Incision is made over the site of maximum tenderness and when pus is found it is mopped away and the abscess explored with a probe. The incision is then enlarged, if necessary, in the appropriate direction and, as in the previous case, a search is made for bare bone. The abscess is also inspected for the presence of slough, which must be removed if loose, but its excision is not recommended.

Volar Infection of Proximal and Middle Segments.These are dealt with as pulp infections. It must be remembered that in the flexion creases there is little fat, and the skin approximates closely to the tendon sheath.

Web Infection. - In the early stage this is manifest by swelling of the adjacent fingers and of the back of the hand and also some separation of the fingers. As in other parts of the hand abscess may be detected by the formation of a subcuticular purulent blister or localized tenderness after the diffuse infection has begun to subside. Incisions are made carefully through skin only and enlarged according to the direction of spread as shown by probing. The most generally useful incision for these infections is one in the overlying flexion crease at the base of the finger.

Carbuncles.-Subcuticular purulent blisters, usually multiple, are a feature of carbuncle, but the chief cause of trouble in these infections is slough. There need be no hurry to open the blisters, as little good will be done until the slough is loose and can be removed. Incisions are not necessary in most cases, but sometimes a large slough can be extracted only after enlarging the spontaneous opening in the skin.

\section{Dressings and Aftercare}

Dry gauze dressings are recommended for all cases, and the patient is instructed not to remove the dressing or to get it wet. The dressing is changed daily until the wound is healing. In paronychia it has been found useful to introduce a little penicillin lactose powder under the elevated nail folds, and in pulp infection with bare bone a little of the powder is packed into the depth of the wound. Paronychia after the formation of pus has ceased requires no dressing unless the nail has been removed, and for early cases without removal of any nail frequent washing with soap and water is recommended after operation.

Persistence of much swelling is an indication for continued splinting and elevation of the limb. Troublesome swelling is commonest in web infections and carbuncles, the swelling being mainly on the back of the hand and fingers. As soon as the signs of infection have subsided, particularly pain and swelling, movement and use of the finger are to be encouraged. If the patient is having antibiotic treatment there appears to be no risk of recurrence of the diffuse stage of the infec- tion. In most cases healing is rapid after pus has been evacuated and slough removed. The commonest cause of delay in healing is the persistence of adherent slough. At the daily dressing the wound must be inspected for slough, which is pulled out when loose. Other possible causes are bone infection, joint infection, and the presence of foreign bodies. Delay in healing also occurs in cases in which a large slough has separated slowly, leaving a cavity which has had time to become somewhat rigid. If there is any doubt about the cause of delay the finger can be $x$-rayed for bone changes or opaque foreign body. But a careful exploration of the wound under ring block and tourniquet is more likely to provide the answer.

A film entitled The Treatment of Infections of the Hand, which was made at the Hand Clinic of University College Hospital, is included in the B.M.A. Film Library and is available on request.

\section{A LIST OF MEDICAL MUSEUMS OF GREAT BRITAIN (1949-50) \\ BY}

\section{J. HACKETT, M.D.}

Secretary, British. Section, International Association of Medical Museums; Director, Wellcome Museum of Medical Science

At the annual general meeting of the British Section of the International Association of Medical Museums in London on December 30, 1948, with Professor Matthew J. Stewart in the chair, it was proposed that a survey of medical museums of Great Britain should be initiated. Copies of a questionary were circulated to members of the association in February, 1949. Additional copies were more widely distributed later in that year, and attempts were made to get further replies in 1950. Returns were obtained from 41 museums in London, 23 in the Provinces, 20 in Scotland, 2 in Wales, and 4 in Ireland. Of these, 5 in London and 4 in the Provinces were either under construction or were exclusively for the use of students of the parent organization, and no details were submitted. There were thus returns from 81 museums for study. Although considerable efforts were made to communicate with all medical museums by inquiry from directors of museums returning the completed questionaries and by reference to directories, it is not certain that all museums were approached. It would be appreciated if the directors of any such museums would write to the Secretary of the British Section of the International Association of Medical Museums, at 183, Euston Road, London, N.W.1.

The present attempt could provide only a list of the medical museums of Great Britain. There is need for a more complete survey of such museums as indicated by Hackett (1949) comparable to that made by Markham (1938) of the smaller museums and art galleries of the British Isles. This could best be done by one individual visiting each museum.

The questionary was headed by this paragraph: "Purpose of Survey: The preparation of a list of medical museums to facilitate visits and interchange of ideas by students and workers in medical museums." Inquiries were made in 20 sections on the following points: Name and address of museum, director and staff ; type of museum ; type of user for whom museum was planned; size and general scheme of museum; 
contents of museum (i.e., specimens, illustrations, diagrams, charts, models, etc.) ; system of classification and identification of specimens ; source of specimens ; availability of microscopical preparations, microscopes, and reference library; facilities for study; accommodation for research work ; facilities for training of technicians ; if regular demonstrations were given in the museum; method of lighting; methods of preservation and mounting; particular strength of museum; annual number of visitors; and by whom the museum was financed. Inquiries were also made for other museums in the area. A second brief questionary was sent out in 1950 asking if the museum was open to all medical graduates and undergraduates without or with permission of the director of the museum, or if the museum was available only to students of the parent body.

Before listing the museums under the above geographical divisions, certain items may be summarized. There were very few full-time directors; the museum duties of most directors were a small part of their activities, which included teaching, routine investigations, research, or other work related to their department or appointment.

\section{Replies to a Questionary}

Over half the museums were said to have been planned for undergraduate and postgraduate students and, in a small number, also for nurses, or were intended for undergraduates and nurses or postgraduates only. The replies to the second questionary showed that over half the museums were accessible only to medical graduates or undergraduates after seeking permission from the director or other person in authority (e.g., dean), while about a quarter were available to these groups without previous permission. A small number were available only to the students of the institutions concerned. Although where permission is necessary it is usually readily granted, there are some teaching hospitals where entrance to their medical museums is barred to all except their chosen few. This may be necessary to protect their own students from the rush of outsiders, who might otherwise monopolize the material, but it seems out of step with the possibility that Britain should become a major centre for postgraduate medical teaching. The lack of an attendant in the museum should not be a hindrance to a more liberal policy, since any technician or graduate on the staff occasionally visiting the museum could, at a glance, identify and warn off any "stranger." A notice on the door indicating the categories for whom the museum is available would probably do much to reduce the possibility of unwanted visitors.

The floor space of over a quarter of the museums was less than 1,000 sq. ft. $\left(92.9 \mathrm{m.}^{2}\right)$, of over a half it was less than $2,000 \mathrm{sq}$. ft. $\left(185.8 \mathrm{~m}^{2}\right)$, and in only 8 was it over 5,000 sq. ft. $\left(464.5 \mathrm{~m}^{2}\right)$.

The most usual arrangement of material was in shelves, cases, cupboards, etc., and in only about a quarter of the museums were bays made use of to increase available display area.

In over three-quarters of the museums it was reported that illustrations, etc., or models, or both, were employed. In over half the museums specimens were classified by anatomical, organ, disease, or aetiological subdivisions ; in the remainder their own, the decimal, or Maude Abbott's classifications were used in about equal numbers. Most replies expressed mild satisfaction with the system in use. The most usual methods of describing specimens were loose-leaf books or labels. Card indices

were used in a few, and in fewer still bound volumes of notes were employed.

At over half the museums microscopes were available, as were microscopical preparations. In about half the museums regular demonstrations were given to classes of students attending the university, medical school, etc. ; in about a further quarter such demonstrations were occasional. In over two-thirds of the replies it was stated that a reference library, facilities for study; accommodation for a limited number of research workers, and facilities for training technicians were available, but, except for the second, these probably applied more to the institution with which the museum was associated than to the museum. In very few museums was daylight the only source of light ; in most it was assisted by fluorescent lamps, filament lamps, or by. both in about equal numbers.

In most museums Kaiserling's method or some modification of it was used to preserve gross specimens. In a few the sodium hydrosulphite method (Wentworth, 1947) was in use. Although in about a third of museums glass jars alone were employed, in nearly a half both glass and "perspex" (methyl methacrylate) containers were in use, and in most of the others perspex only was used. About half the museums were considered by their directors to contain material worthy of visits by interested persons outside the museum area. In returns from 71 museums the date of foundation was given ; 4 were founded in the eighteenth century, 29 in the nineteenth, and the remainder were equally divided between the first and second 25 years of the present century.

\section{Alphabetical List}

The following is an alphabetical list of 36 museums in London, 19 in the English Provinces, 20 in Scotland, and 2 each in Wales, Northern Ireland, and Eire. Those museums open to medical graduates and undergraduates without previous permission are indicated by an asterisk. The figures in brackets after each museum are the date of founding of the museum and the area of its floor space.

\section{London}

Central Histological Laboratory, Whittington

Chelsea Hospital for Women, Dovehouse Street, S.W.3

*Guy's Hospital Medical School, Gordon Museum, S.E.1

Hospital for Sick Children, Great Ormond Street, W.C.1

Institute for Diseases of the Chest, Brompton Hospital, Brompton Road, S.W.3

Institute of Laryngology and Otology, 330, Gray's Inn Road, W.C.1

*Institute of Ophthalmology, Judd Street, W.C.1

Institute of Orthopaedics, Royal National Orthopaedic Hospital, 234, Great Portland Street, W.1

Institute of Psychiatry, Maudsley Hospital, Denmark Hill, S.E.5
Pathological (1933; 1,600 sq. ft., $148.6 \mathrm{~m}^{2}$ )

Pathological-of female generative system. $(1930 ; 800$ sq. ft., $74.3 \mathrm{~m} .{ }^{2}$ )

Pathological, a n a t o mi c a 1 , dermatological, and dental, with some historical material relating only to Guy's Hospi- tal. $(1905 ; 14,700$ sq. ft., 1,365.7 m. ${ }^{2}$ )

Pathological, historical. (1853; 1,200 sq. ft., $111.5 \mathrm{~m}^{2}$ )

Pathological and radiological of diseases of the chest. $\left(1880 ; 800\right.$ sq. ft., $\left.74.3 \mathrm{~m}^{2}{ }^{2}\right)$

Pathological (ear, nose, and throat) with some clinical and surgical material. (1946; 1,200 sq. ft., $111.4 \mathrm{~m}^{2}{ }^{2}$ )

Pathological. (1857; 350 sq ft., $32.5 \mathrm{~m}^{2}$ )

Pathological, clinical, and surgical (orthopaedic)

1. Pathology of central nervous system. 2. Guttmann-Maclay Collection. Art in mental disorder and allied bibliographia. (1951; 300 sq. ft. $27.9 \mathrm{m.}^{2}$ ) 


\section{London.- - cont.}

London Hospital Medical College Mustum, Turner Street, Mile End, E.1

National Heart Hospital, Westmoreland Street, W.1

National Hospital for Diseases of the Nervous System, Queen Square, W.C.1

North Middlesex Hospital, Silver Street, Edmonton, N.18

Postgraduate Medical School of London, Hammersmith Hospital, Ducane Road, W.12

*Prince of Wales's General Hospital, Tottenham, N.15

Queen Charlotte's Hospital, 339, Goldhawk Road, W.6

Royal Army Medical College, Millbank, S.W.1

Royal Cancer Hospital, Fulham Road, S.W.3

*Royal College of Surgeons, Lincoln's Inn Fields, W.C.2

Royal Free Hospital School of Medicine, 8, Hunter Street, Brunswick Square, W.C.1

* Royal Sanitary Institute, Parkes Museum of Hygiene, 90, Buckingham Palace Road, S.W.1

St. Bartholomew's Hospital Medical College, West Smithfield, E.C.1

St. George's Hospital Medical School, Hyde Park Corner, S.W.1

*St. Mark's Hospital, City Road, E.C.1

St. Mary's Hospital Medical School, Paddington, W.2

*St. Peter's Hospital for Stone, 10, Henrietta Street, Covent Garden, W.C.1

St. Thomas's Hospital Medical School, The Shattock Museum, S.E.1

University College Hospital Medical School, Gower Street, W.C.1

*Wellcome Historical Medical Museum, 28, Portman Square, W.1

*Wellcome Museum of Medical Science, 183 1 193, Euston Road, N.W.1

West End Hospital for Nervous Diseases, Welbeck Street, W.1

Westminster Hospital Medical School, 17, Horseferry Road, S.W.1
Pathological, clinical, surgical, dental, parasitological, anat o m i c a l, pharmaceutical, preventive medicine, and industrial medicine. (1854; 7,200 sq. ft., $668.9 \mathrm{~m}^{2}$ )

Pathological. $(1930 ; 300$ sq ft., 27.9 m. $^{2}$ )

Pathological. $(1920 ;-)$

Pathological, clinical, surgical, gynaecological, and anatomical. $(1947 ; 360$ sq. ft., $33.4 \mathrm{~m} .^{2}$ )

Pathological. (1935; 800 sq ft., $74.3 \mathrm{m.}^{2}$ )

Pathological. (-; 200 sq. ft., $18.6 \mathrm{~m}^{2}$ )

Pathological, clinical, and surgical - mostly obstetrica

1. Pathological with tropical medicine bias. $(1904 ; 2,000$ sq. ft., $185.8 \mathrm{~m}^{2}$ )

2. Preventive medicine and hygiene with special reference to Army health. (Admission by application to Commandant R.A.M. College.) $(1914 ; 3,000$ sq. ft. $278.7 \mathrm{m.}^{2}$ )

Pathological. (1898; 360 sq ft., $33.4 \mathrm{~m}^{2}$ )

Anatomical (including odontological) and pathological $(1800 ; 7,700$ sq. ft., 715.3 m. $\left.{ }^{2}\right)$

1. Anatomical. 2. Pathological. $(1879 ; 1,100$ sq. ft. $102.2 \mathrm{~m} .^{2}$ )

Hygiene. (1876; 2,700 sq. ft., $250.8 \mathrm{~m}^{2}$ )

Pathological. (1726; 2,800 sq ft., $260.1 \mathrm{~m}^{2}$ )

Pathological. (1835; 1,200 sq ft., $111.4 \mathrm{~m}^{2}$ )

Pathological (diseases of rectum). (1926; - )

Pathological. (1855; 900 sq. ft., $83.6 \mathrm{~m}^{2}$ )

Pathological (u rologi c a l). $(1930 ;-)$

Pathological, clinical, medical, and surgical. (1847; 2,700 sq. ft., $\left.250.8 \mathrm{~m} .^{2}\right)$

1. Anatomical. (New Museum $1946 ; 1,070$ sq. ft., $\left.99.4 \mathrm{m.}^{2}\right)$

2. Morbid anatomy and historical relating to U.C.H. (1907 ; 2,600 sq. ft., $\left.241.5 \mathrm{~m}^{2}{ }^{2}\right)$

Historical. (1913; 2,300 sq. ft., $\left.213.7 \mathrm{~m}^{2}{ }^{2}\right)$

Medical sciences. (1912; 4,500 sq. ft., 418 m. $^{2}$ )

Pathological (neurological). $(1920 ;-)$

Primarily pathological, with morbid anatomical specimens illustrating clinical medicine and surgery. $(1849 ; 1,600$ sq. ft., 148.6 m. ${ }^{2}$ )

\section{Provinces}

Birmingham

Birmingham Medical School, Pathological, clinical, surgical, Birmingham, 15 dental, anatomical, and anthropological. (1938; 7,200 sq. ft., $668.9 \mathrm{~m}^{2}{ }^{2}$

Bristol

Pathological Museum, Univer- Pathological. (1826; 2,300 sq. sity of Bristol

ft., $213.7 \mathrm{~m}^{2}$ )

\section{Cambridge}

Anatomy School, University of Anatomical and anthropologiCambridge

cal. $(1804 ; 4,050$ sq. ft. $\left.376.3 \mathrm{~m} .^{2}\right)$

*Humphry Museum, Department of Pathology, Tennis Court Road, Cambridge

Pathological. . (1891; 1,150 sq. ft., $106.8 \mathrm{~m}^{2}$ )

Leeds

St. James's Hospital, Leeds, 9 Pathological, clinical, and surgical. $(1929 ; 360$ sq. ft., $33.4 \mathrm{~m} .^{2}$ )

University of Leeds, School of

*1. Anatomical. (1887; - )

2. Pathological, including all specialties. $(1904 ; 6,340$ sq. ft., $589 \mathrm{m.} .^{2}$ )

3. Forensic medicine. (1947; 一)

Liverpool

*Department of Pathology, Pathological. (1844; 1,300 sq. University of Liverpool

*University of Liverpool, 126, Mount Pleasant, Liverpool, ft., $120.1 \mathrm{~m}^{2}$ )

Preventive medicine and historical. $(1897 ; 5,700$ sq. ft., $529.6 \mathrm{~m}^{2}$ )

\section{Manchester}

Anatomy Department, Man- Anatomical, with small historichester

cal and dental sections. (1874; 3,000 sq. ft., 278.7 m. ${ }^{2}$ )

Department of Pathology, Pathological. (1927; 1,800 sq. York Place, Manchester, $13 \quad$ ft., $167.2 \mathrm{~m}^{2}{ }^{2}$ )

\section{Newcastle-upon-Tyne}

Dental Museum, Sutherland Dental School, King's College, Newcastle-upon-Tyne, 1

Dental (pathological, clinical, anatomical - human and comparative-and historical). (1895; 1,900 sq. ft., 176.5 $\left.\mathrm{m} .{ }^{2}\right)$

*Pathological Museum, Medical School, King's College, Newcastle-upon-Tyne, 1

At present pathological, but it is intended to make it a general medical museum. $(1840 ; 2,200$ sq. ft., 204.4 m. ${ }^{2}$ )

*Pathological Museum, Royal Pathological. (1948; 800 sq. Victoria Infirmary ft., $74.3 \mathrm{~m}^{2}$ )

Pathological Museum of Pathological. (1900; 1,000 sq. Oxford University, Radcliffe ft., $92.9 \mathrm{m.}^{2}$ )

Infirmary

Sheffield Royal Infirmary

Sheffield

Pathological (medical and surgical) with essential parasites or organs of parasitological interest. $(1934 ; 100$ sq. ft., $9.3 \mathrm{~m}^{2}$ )

University of Sheffield, 1. Anatomical. (1905; 550 sq. Sheffield, 10 ft., $\left.51.1 \mathrm{~m} .^{2}\right)$

2. Pathological. (About 1900 1,080 sq. ft., $100.3 \mathrm{~m}^{2}{ }^{2}$

\section{Scotland}

\section{Aberdeen}

University of Aberdeen, Anatomical and anthropoMarischal College, Aberdeen logical. (1860; 2,500 sq. ft., $\left.232.2 \mathrm{~m}^{2}\right)$

*University of Aberdeen, Pathological, clinical, and Fosterhill, Aberdeen surgical. $(1938 ; 4,600 \mathrm{sq}$

ft., $427.4 \mathrm{m.}^{2}$ ) 


\section{Scotland.-cont}

Dundee

*Department of Pathology Medical School, Dundee

Dundee Dental School, University of St. Andrews, Park Place, Dundee

Forensic Medicine Department, Medical School, Dundee

St. Andrews University Surgery Museum, Small's Wynd, Dundee, Angus

University College, Department of Anatomy, Dundee

Pathological. (1902; 850 sq ft., $79 \mathrm{m.}^{2}$ )

Dental. (一; 2,200 sq. ft., $204.4 \mathrm{m.}^{2}$ )

Forensic medicine

Surgical. (1933; 400 sq. ft., $37.2 \mathrm{~m}^{2}$ )

Anatomical. (1887; 1,400 sq ft., $130 \mathrm{~m}^{2}{ }^{2}$

\section{Edinburgh}

* Royal College of Surgeons Museum, Royal College of Surgeons, 18, Nicolson Street, Edinburgh, 8

University of Edinburgh, University New Buildings, Teviot Place, Edinburgh

*Usher Institute, Harrenden Park Road, Edinburgh, 9

Primarily surgical pathology with dental, ophthalmological, anatomical, and historical sections $(1804 ; 7,800$ sq ft., $724.6 \mathrm{~m}^{2}$ )

*1. Anatomical, including considerable collections of com parative anatomy, and lesser ones of pathology. (1798 $6,000$ sq. ft., 557.4 m. $)$

2. Forensic medicine, largely pathological. (-; 1,500 sq ft., $139.4 \mathrm{~m}^{2}$ )

3. Materia medica. (Early 19th century ; -)

4. Surgical pathology. (1924; 600 sq. ft., $55.7 \mathrm{m.}^{2}$ )

Public health and industrial medicine. $(1902 ;-)$

\section{Glasgow}

Department of Anatomy, University of Glasgow, Glasgow, W 2

Glasgow Royal Infirmary, Glasgow, C.4

Glasgow Royal Maternity and Women's Hospital, Rottenrow, Glasgow, C.4

Institute of Pathology, Royal Hospital for Sick Children, Yorkhill, Glasgow, C.3

Mearnskirk Hospital Museum,

Newton Mearns, Glasgow

Western Infirmary, Glasgow

Anatomical and pathological (1783; 3,000 sq. ft., 278.7 $\left.\mathrm{m} .{ }^{2}\right)$

Pathological. (1908; 2,400 sq ft., $223 \mathrm{~m}^{2}$ )

Pathological and clinical (1908; 700 sq. ft., 65 m. $^{2}$ )

Pathological. (1924; 1,300 sq ft., $120.8 \mathrm{m.}^{2}$ )

Pathological. (1930; 400 sq ft., $37.2 \mathrm{~m} \cdot{ }^{2}$ )

Pathological. (1870; $1,600 \mathrm{sq}$ ft., $148.6 \mathrm{m.}^{2}$ )

\section{St. Andrews}

Bute Anatomical Museum, Anatomical. (1899; 1,000 sq Bute Medical Buildings, ft., $92.9 \mathrm{m.}^{2}$ )

St. Andrews

\section{Wales \\ Cardiff}

University College, The Alfred Hughes Museum, Department of Anatomy, Newport Road, Cardiff

Welsh National School of Pathological. (1916; 1,750 sq. Medicine, Royal Infirmary, Cardiff

\section{Northern Ireland} Belfast

*The Queen's University, 1. Anatomical and clinical. $(1860 ; 4,400$ sq. ft. 408.8 $\mathrm{m} .^{2}$ )

2. Pathological. (1935; 1,800 sq $\mathrm{ft} . .167 .2 \mathrm{~m}^{2}$ )

\section{Eire}

Trinity College, Dublin

1. Anatomical. $(1889 ; 1,600$
Replies to a questionary were received from 81 medical museums in Great Britain. A brief summary of these returns and a list of the museums has been made. There is need for a more complete survey of them, based upon the visits of one or at most only a few observers.

\section{REFERENCES}

Hackett, C. J. (1949). Bull. int. Ass. med. Mus., 30, 114

Markham, S. F. (1938). A Report on the Museums and Art Galleries of the British Isles (other than the National Museums). Constable, Edinburgh.

Wentworth, J. E. (1947). Bull. int. Ass. med. Mus., 27, 201.

\section{MEDICAL BIRTHDAY HONOURS}

The names of the following members of the medical profession were included in a Birthday Honours List published in Supplements to the London Gazette on June 7:

\section{K.C.V.O}

Geoffrey Sydney Todd, C.V.O., O.B.E., M.B., Ch.M., F.R.C.P. Medical Superintendent, King Edward VII Sanatorium, Midhurst, Sussex.

\section{D.B.E. (Civil Division)}

Hilda Nora Lloyd, M.B., Ch.B., F.R.C.S. President of the Royal College of Obstetricians and Gynaecologists. Professor of Obstetrics and Gynaecology in the University of Birmingham from 1944 to 1950 .

\section{Knighthood}

Charles Arthur Lovatt Evans, D.Sc., Hon.LL.D., F.R.C.P., F.R.S. Emeritus Professor of Physiology in the University of London.

ERNest Frederick Finch, M.D., M.S., F.R.C.S. Professor of Surgery in the University of Sheffield from 1934 to 1944; Vice-President of the Royal College of Surgeons of England. For services to surgery and medical education.

John William McNeE, D.S.O., D.Sc., M.D., F.R.C.P., F.R.C.P.Ed., F.R.F.P.S. Regius Professor of the Practice of Medicine in the University of Glasgow since 1936; Physician to H.M. Household in Scotland; Consulting Physician to the Royal Navy in Scotland.

Philip Santo Messent, M.S., F.R.A.C.S. Director of Surgical Studies, University of Adelaide, South Australia.

\section{C.B. (Military Division)}

John Mandeville Macfie, C.B.E., M.C., M.B., Ch.B. MajorGeneral, late R.A.M.C. Honorary Surgeon to the King.

\section{C.M.G.}

John Merrill Cruickshank, O.B.E., M.D., F.A.C.P., F.A.C.S., Colonial Medical Service. Director of Medical Services, Fiji, and Inspector-General, South Pacific Health Service.

JohN William FIELD, M.D., Colonial Medical Service. Director of the Institute for Medical Research, Federation of Malaya.

HERBERT JoHN SEDDON, D.M., F.R.C.S. Member of the Colonial Advisory Medical Committee; Clinical Director of the Royal National Orthopaedic Hospital; Nuffield Professor of Orthopaedic Surgery in the University of Oxford and Clinical Director of the Wingfield-Morris Hospital from 1940 to 1948.

$$
\text { C.V.O. }
$$

Alexander Greig Anderson, M.D., F.R.C.P. Physician to H.M. Household in Scotland; Consulting Physician, Aberdeen Royal Infirmary.

George Ritchie Mather Cordiner, M.B., Ch.B., D.M.R.E Honorary Radiologist, St. George's Hospital, London.

\section{C.B.E. (Military Division)}

William EdWard Barnes, M.R.C.S., L.R.C.P., D.T.M.\&H., Air Vice-Marshal, R.A.F.

William Alexander Duncan Drummond, O.B.E., F.R.C.S. D.L.O. Colonel, late R.A.M.C.

\section{C.B.E. (Civil Division)} sq. ft., $148.6 \mathrm{~m}^{2}$ )

2. Pathological. (1898; 900 sq. ft.. $83.6 \mathrm{~m}^{2}$ )
Thomas Beaton, O.B.E., M.D., F.R.C.P. Physician-Superintendent, St. James Hospital, Milton, Portsmouth, and Medical Director, Mental Health Service, Portsmouth. 